\title{
Bright environmental light improves the sleepiness of nightshift ICU nurses
}

\author{
John E. Griepentrog ${ }^{1}$, Hanna E. Labiner ${ }^{1}$, Scott R. Gunn² and Matthew R. Rosengart ${ }^{1,2^{*}}$
}

\begin{abstract}
Background: Shift work can disturb circadian homeostasis and result in fatigue, excessive sleepiness, and reduced quality of life. Light therapy has been shown to impart positive effects in night shift workers. We sought to determine whether or not prolonged exposure to bright light during a night shift reduces sleepiness and enhances psychomotor performance among ICU nurses.

Methods: This is a single-center randomized, crossover clinical trial at a surgical trauma ICU. ICU nurses working a night shift were exposed to a 10-h period of high illuminance (1500-2000 Ix) white light compared to standard ambient fluorescent lighting of the hospital. They then completed the Stanford Sleepiness Scale and the Psychomotor Vigilance Test. The primary and secondary endpoints were analyzed using the paired $t$ test. A $p$ value $<0.05$ was considered significant.
\end{abstract}

Results: A total of 43 matched pairs completed both lighting exposures and were analyzed. When exposed to high illuminance lighting subjects experienced reduced sleepiness scores on the Stanford Sleepiness Scale than when exposed to standard hospital lighting: mean (sem) 2.6 (0.2) vs. 3.0 (0.2), $p=0.03$. However, they committed more psychomotor errors: 2.3 (0.2) vs. 1.7 (0.2), $p=0.03$.

Conclusions: A bright lighting environment for ICU nurses working the night shift reduces sleepiness but increases the number of psychomotor errors.

Trial registration: ClinicalTrials.gov, NCT03331822. Retrospectively registered on 6 November 2017.

Keywords: Light, Circadian, Shift work sleep disorder, Night shift, Nurse

\section{Background}

Shift work, work that occurs outside a timeframe of approximately $0600-1800 \mathrm{~h}$, causes a disruption of circadian biology and underlies what is called shift work sleep disorder (SWSD) [1]. SWSD is characterized by insomnia, fatigue, and excessive sleepiness, and can lead to reduced work performance, processing errors, accidents, absenteeism, and reduced quality of life [2]. The American Academy of Sleep Medicine estimates the prevalence of SWSD to be $5-8 \%$, with night shift workers being affected the most [3]. The significance is underscored when viewed in the context of industrialized nations, in which shift workers comprise more than $20 \%$ of the workforce $[4,5]$. For a field like healthcare that functions

\footnotetext{
* Correspondence: rosengartmr@upmc.edu

${ }^{1}$ Department of Surgery, University of Pittsburgh, 200 Lothrop Street - Suite F1266.1, Pittsburgh, PA 15213, USA

2Department of Critical Care Medicine, University of Pittsburgh, Pittsburgh,
} PA, USA

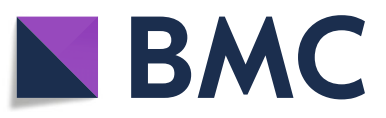

(c) The Author(s). 2018 Open Access This article is distributed under the terms of the Creative Commons Attribution 4.0 International License (http://creativecommons.org/licenses/by/4.0/), which permits unrestricted use, distribution, and

reproduction in any medium, provided you give appropriate credit to the original author(s) and the source, provide a link to the Creative Commons license, and indicate if changes were made. The Creative Commons Public Domain Dedication waiver (http://creativecommons.org/publicdomain/zero/1.0/) applies to the data made available in this article, unless otherwise stated. of SWSD is likely much higher [6]. Thus, the ramifications of SWSD for the workforce that enables and maintains 24-h healthcare are likely many and profound.

Night shift work forces individuals to work at a time when the circadian sleep drive is high and to sleep when wakefulness is high. This misalignment induces poor daytime sleep and impaired nighttime alertness [7]. Alertness and overall performance reach a nadir in the early morning, yielding reduced work efficiency and a period of increased vulnerability to the commission of errors [8-10]. Inefficient daytime sleep leads to continued reduced night shift alertness and performance, and a vicious cycle of circadian malalignment ensues. Not surprisingly, several interventions have been studied as measures to counter the degradation in fatigue and foster improved sleep post-shift - bright light, naps, and caffeine. 
The paradigm that environmental light can be manipulated to modulate circadian biology, physiology, and human performance is not new and possesses biologic plausibility [11, 12]. Light is the dominant environmental cue entraining circadian rhythms, and the prototypical mediator is melatonin [13]. With the commencement of the solar day, light travels through a nonvisual optic pathway to suppress melatonin production and bring on wakefulness and alertness [14]. The reverse occurs upon darkness. Shiftwork perturbs circadian homeostasis, and considerable research has focused upon light therapy, circadian biology, and health [5, 15-17]. Bright light even of short duration has been shown to impart acute positive effects in night shift working nurses, including heightened subjective alertness and reduced insomnia, anxiety, and depression [18]. However, the ramifications of light therapy on nursing performance remain to be completely defined [19]. Herein we conducted a randomized crossover clinical trial to address the hypothesis that exposure to bright light reduces post-shift sleepiness and enhances vigilance and psychomotor performance among ICU nurses working a night shift.

\section{Methods}

\section{Study design}

This is a randomized, crossover clinical trial (NCT03331822) to address the hypothesis that high illuminance light improves vigilance and psychomotor speed while reducing sleepiness among ICU nurses working a night shift. There are two wings to the ICU (F wing and $\mathrm{G}$ wing), each with a different geography and perceived potential for varying acuity and magnitude of ICU care (Fig. 1). Thus, we conducted the trial in two phases so as to administer the intervention and the control within each of the two ICU wings. An initial phase was conducted in which the $G$ wing served as the bright light interventional arm and the $\mathrm{F}$ wing delivered the standard light and served as the control arm. Upon completion of this phase, a crossover trial commenced in which the conditions were flipped to the other ICU wing. Thus, for the entire trial, both ICU wings produced both light settings.

\section{Subjects}

Eligible subjects were nurses working a night shift (1900-0700 h) in the Surgical Trauma Intensive Care Unit (ICU) at the University of Pittsburgh Medical Center (UPMC) Presbyterian Hospital. Trial enrollment occurred between 1 October and 1 December 2017. This study was approved by the Institutional Review Board (IRB) at the University of Pittsburgh (PRO\#17010109). Subjects were enrolled after written informed consent was obtained.

\section{Baseline characteristics}

For each subject we recorded baseline demographics and pertinent characteristics. Visual acuity was self-reported and typically based upon outpatient optometry/ophthalmology

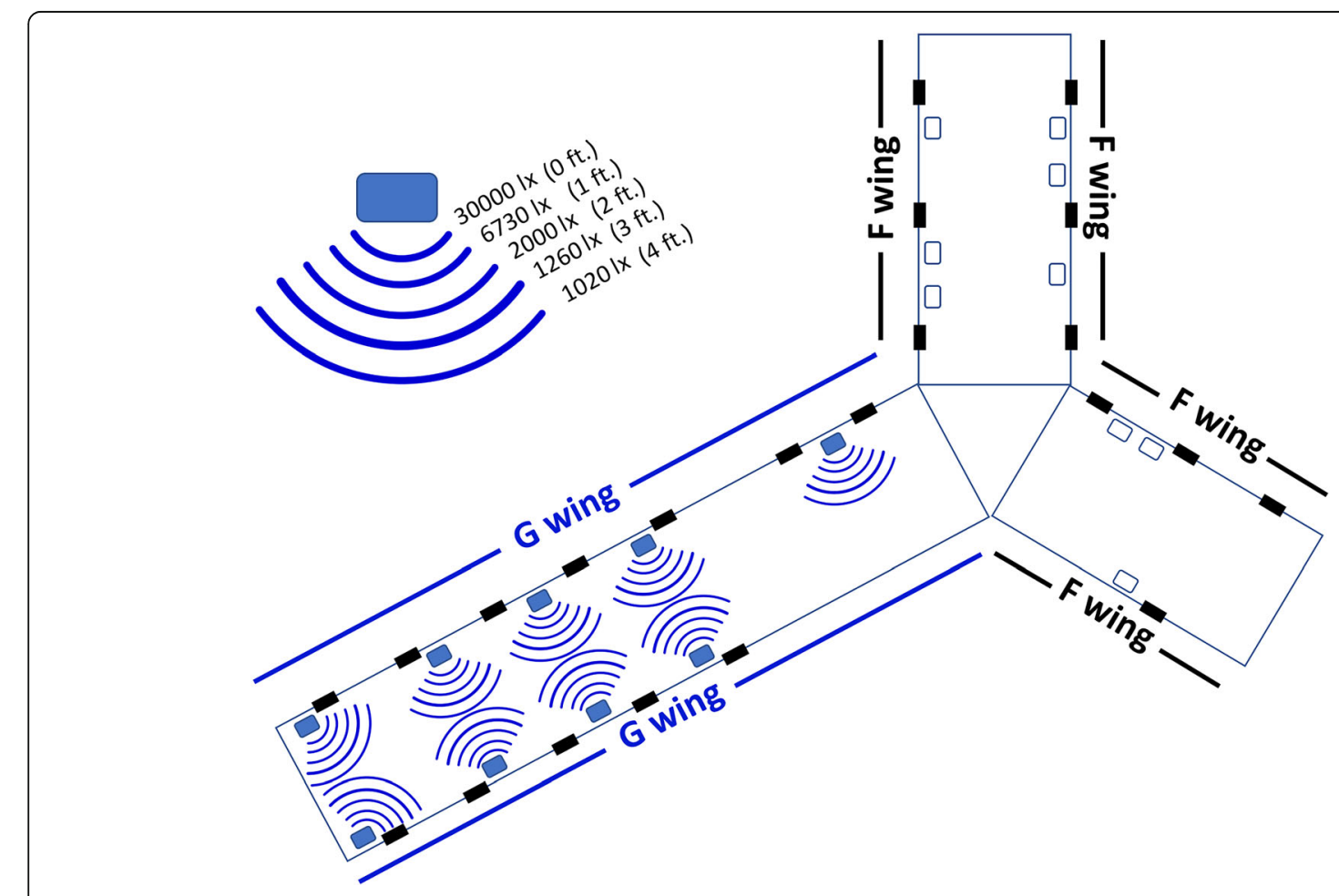

Fig. 1 Map of illuminance topography 
visits. The use of over-the-counter and prescription sleep aids was self-reported.

\section{Randomization}

Subjects were assigned in a crossover design to be exposed to both the control and the intervention during each phase of the study. Specifically, for each night shift, nurses were assigned to one of two wings of the ICU (F side or $\mathrm{G}$ side) that each had been fitted to provide a distinct lighting exposure: (1) continuous high illuminance white light or (2) the standard, ambient white, fluorescent hospital lighting (Fig. 1). Allocation to either exposure was dictated by the monthly ICU nursing schedule, an established process to staff the ICU that has been performed for years and that occurred independent of our trial design and implementation. Specifically, the nursing assignments to fully staff the ICU are generated well in advance in month-long blocks. For each night, a nurse is assigned to paired beds within one wing of the ICU. Thus, their assignment to either control or intervention was based upon nursing bed assignment. After 4 weeks the lighting exposure layout was flipped and allocation to either intervention or control was again dictated by the monthly ICU nursing assignment. Subjects completing night shifts on both the $\mathrm{F}$ and $\mathrm{G}$ wings, and thus receiving both exposures, served as matched pairs for analysis.

\section{Intervention}

Before randomization each subject was exposed to the ambient white, fluorescent hospital lighting (emission 300 lux (lx), color temperature 3500-4100 K, 100\% UV filtration). The "standard" lighting group continued to be exposed to this ambient white, fluorescent lighting for the duration of each 12-h night shift (1900-0700 h, on 2 October 2017: circadian time CT 1142-2341 (circadian day 0719-1900 h)). The "high" illuminance intervention group was additionally exposed to a Day"Light Classic Light (emission 10,000 lx, color temperature $4000 \mathrm{~K}$, 99.3\% UV filtration). The light was positioned outside the ICU room at each nursing work station and directed away from the patient bed, thereby shielding the patients from the experimental conditions. Illuminance was maximal at the work station and linearly degraded with increasing distance (Fig. 1). The density and geographic distribution of lighted stations generated a minimal environmental illuminance exceeding $1000 \mathrm{~lx}$ for the entire lighted ICU wing. This configuration exposed each nurse positioned within $24 \mathrm{in}$. of a work station to an illuminance of 1500-2000 lx (Fig. 1). This high illuminance intervention was initiated at $1900 \mathrm{~h}$ and discontinued at $0500 \mathrm{~h}$, generating a 10-h exposure period. For the remaining $2 \mathrm{~h}$ of the shift (0500-0700 h) the high illuminance cohort was exposed to ambient white, fluorescent lighting as previously described. Though we did not quantify the lighting exposure of each subject, nurses typically spend the majority of the shift within their assigned ICU wing. Nurses assigned to one wing and exposed to one intervention group were geographically separated from the other group.

\section{Outcomes}

Our primary outcomes were the Stanford Sleepiness Scale (SSS) and the number of lapses and errors on the Psychomotor Vigilance Test (PVT) [20]. The standard night shift occurs during the interval 1900-0700 h. We perceived that times nearing the conclusion of the shift comprise a period of potentially increased vulnerability, insofar as reduced vigilance and performance errors may be concerned. Thus, we chose a distinct time of $0500 \mathrm{~h}$, which is $2 \mathrm{~h}$ prior to the end of the shift to administer the tests, and all participants were administered the tests at this same time. This time coincides with the immediate termination of the intervention, and thus there is no gap from exposure to measurement, which should minimize bias. Secondary outcomes included median response time domains of the PVT and salivary melatonin concentration.

\section{Psychomotor Vigilance Task (PVT)}

Each subject completed the PVT $2 \mathrm{~h}$ prior to the conclusion of the night shift $(0500 \mathrm{~h})$. The PVT is a validated and sensitive test that assesses the cognitive domains of vigilant attention and psychomotor speed as quantitative parameters of partial and total sleep deprivation [21]. It has been employed as a marker of attention deficit in hundreds of studies to date [21, 22]. It is a 3-min test in which the subjects look at a small rectangular screen and press the mouse every time numbers appear. The number of lapses (responses greater than $500 \mathrm{~ms}$ ) is recorded. For the PVT, participants must maintain vigilant attention on a target box, respond as quickly as possible to the appearance of a stimulus, and avoid responding prematurely. The stimulus is a millisecond timer, and the reaction time in milliseconds is shown as feedback after each response. A total of 28 metric data fields are generated [21]. The "aggregate score" is a calculated metric of the PVT that penalizes based on the percentage of responses that were lapses and the percentage of responses that were early response errors. It is quantified with the following formula:

Aggregate score $=(1-(\text { Lapses } / \text { Responses })-(\text { Errors } / \text { Responses }))^{*} 100$

The "efficiency" score is a summary estimate that deducts for false starts and long responses. An "error" is recorded by either a false start or a coincident false start, 
and the parameter "errors" is the sum of total errors (i.e., false starts and coincident false starts).

\section{Melatonin concentration}

Saliva samples were collected from each subject at the start and conclusion of each shift (1900 and $0700 \mathrm{~h}$ ) using a commercially available kit (Sarstedt Salivette Cotton Swabs 50-809-199, Fischer Scientific, Hampton, NH, USA) [23]. Samples were immediately snap frozen and stored at $-80{ }^{\circ} \mathrm{C}$ for future analysis of melatonin concentrations. Sample melatonin concentrations were assayed using a commercially available enzyme-linked immunosorbent assay (ELISA) for human melatonin (LS Bio $\mathrm{Hu}-$ man Melatonin ELISA (competitive EIA)- LS-F39279-1, LifeSpan Biosciences Inc., Seattle, WA, USA).

\section{Stanford Sleepiness Scale}

Subjects completed the SSS $2 \mathrm{~h}$ prior to the end of each shift $(0500 \mathrm{~h})$. The SSS is a simple 7 -point rating scale developed by Hoddes et al. [24] It has become the validated, gold standard for measuring subjective sleepiness levels and has been used in over 100 clinical trials $[25,26]$.

\section{Statistical analyses}

All analyses followed the intention-to-treat principle. The study was powered to detect a 1-point change in the SSS scores between lighting assignments. A 1-point difference was determined by consensus among the investigators as a feasible and relevant endpoint. There is no established minimal clinically important difference for this endpoint, though this magnitude of change is in accordance with other studies assessing sleepiness in the context of day and night clinical duties [25]. Assuming a mean SSS score of 2.7 (standard deviation (SD) 1.1), $\beta$ of 0.80 , and two-sided $\alpha$ of 0.05 , an estimated 12 matched pairs were needed. Each of the two phases of the trial had a planned enrollment of 20 matched subjects. Thus, we anticipated enrolling approximately 40 matched pairs, which would provide $80 \%$ power to detect a statistically significant difference in effect size of 0.50 in SSS scores. We did not interfere with the nursing assignments, and thus each nurse may work several nights assigned to either the intervention or control arms. In these circumstances in which a subject could potentially contribute multiple results for an exposure (e.g., assigned to several night shifts over the study period), we calculated and analyzed the mean subject parameter scores for each lighting exposure (i.e., ICU wing). Thus, for each participating nurse only one pair of matched data were analyzed for each phase of the trial: (1) a single data set for exposure to the bright light intervention and (2) a single data set for the exposure to the control standard light arm. The primary and secondary endpoints were analyzed using the paired $t$ test. Data were analyzed using STATA SE 14.

\section{Results}

A total of 31 subjects were randomized and completed both lighting exposures. Twelve subjects were enrolled in both phases of the trial, and thus a total of 43 matched pairs comprised the entire cohort for analysis of primary and secondary outcomes (Fig. 2). The median (IQR) age was 29 years (IQR, 26-32 years) and 22 (71\%) were female. The median corrected visual acuity of the entire cohort was 20/20 (IQR, 20/20-20/30). Five subjects (16\%) utilized nightly melatonin, and five (16\%) utilized additional sleep aids.

Exposure to high illuminance lighting relative to standard hospital lighting significantly reduced subjective sleepiness at the end of the night shift as quantified by the SSS: mean (sem) SSS $2.6(0.2)$ vs. $3.0(0.2)$, mean difference $-0.4(0.2), p=0.03$ (Fig. 3). However, after exposure to high illuminance lighting, subjects committed more errors: mean (sem) 2.3 (0.2) vs. 1.7 (0.2), mean difference, $0.6(0.3), p=0.03$ than after exposure to standard hospital lighting. There were no significant differences in number of lapses or in mean or median response times (Fig. 3).

A total of eight subjects completed paired salivary sample acquisition. Exposure to bright light suppressed early morning salivary melatonin concentrations to a greater degree than standard lighting, though this was not statistically significant: 15 (4.9) pg/mL vs. 44 (32) pg/mL, mean difference -29 (32), $p=0.39$ (Fig. 4).

\section{Discussion}

The number of shift workers in industrialized nations is increasing to over $20 \%$ of the workforce [5]. In most intensive care units, nurses work 12 -h shifts that consist of days and nights. Shift work has been reported to cause fatigue, induce sleep disorders, and cause metabolic disturbances. Exposure to bright light has been shown to improve the subjective symptoms of night shift work, such as sleepiness and vigor [5, 27]. Here we observed that prolonged exposure to high-intensity lighting during the night reduced post-shift subjective sleepiness among ICU nurses but resulted in more errors; there was no significant effect on other parameters of the PVT such as lapses and response times. Thus, although continuous bright light during the scotophase may contribute to improving nursing wakefulness, it does not appear to improve performance, and our data suggest it may worsen it.

Alertness and overall performance in diurnal creatures are degraded as the early morning approaches, increasing the susceptibility to committing errors and reducing work efficiency [8-10]. This fact provided the impetus 


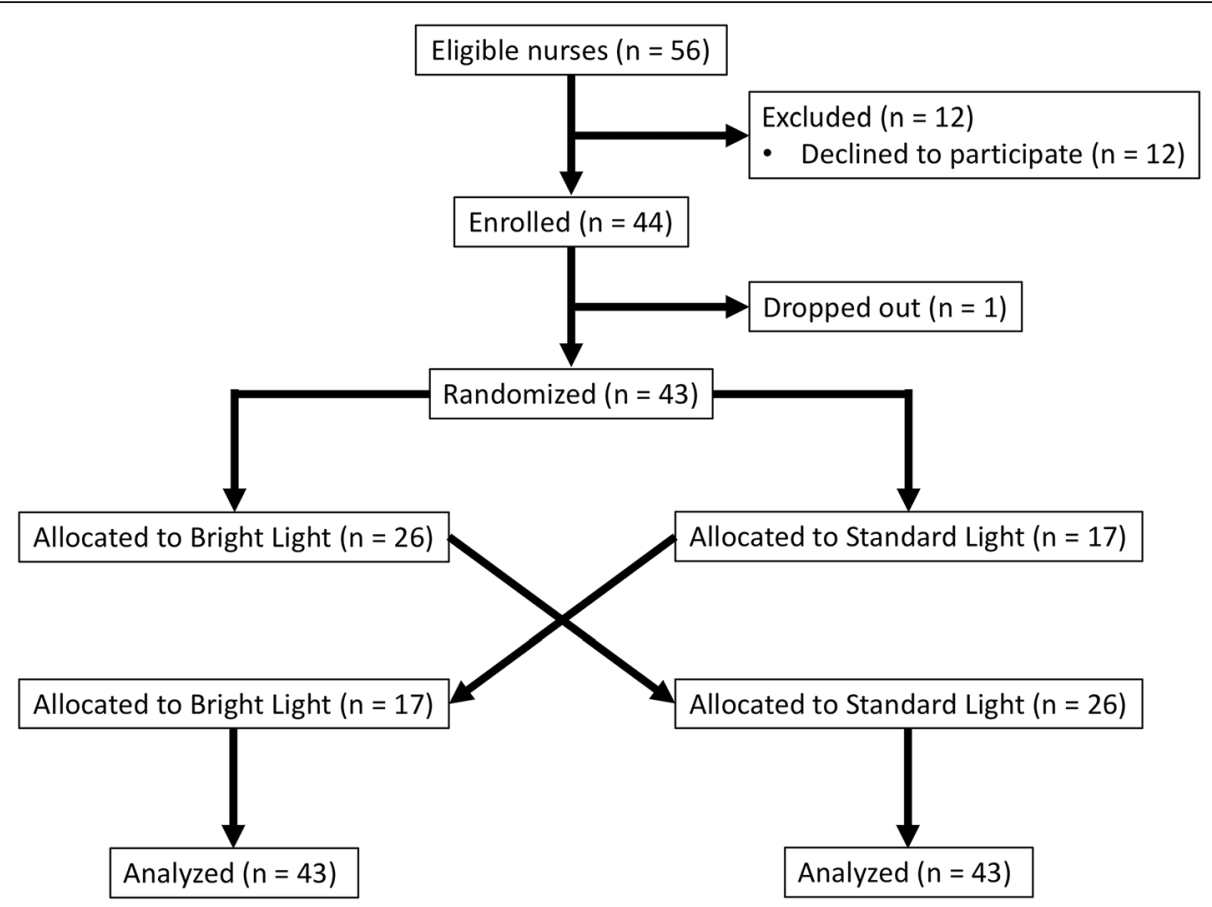

Fig. 2 Consolidated Standards of Reporting Trials (CONSORT) diagram

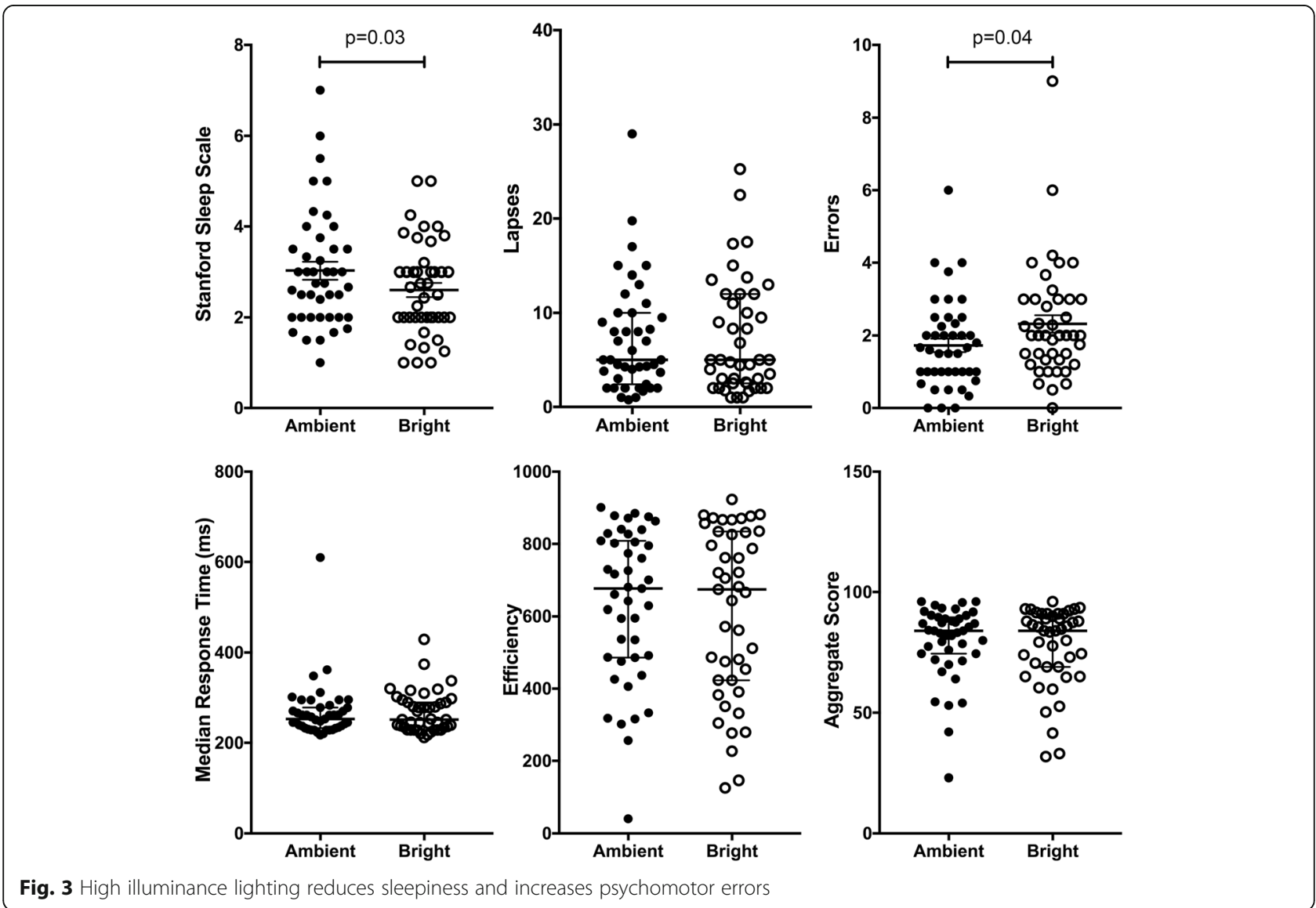




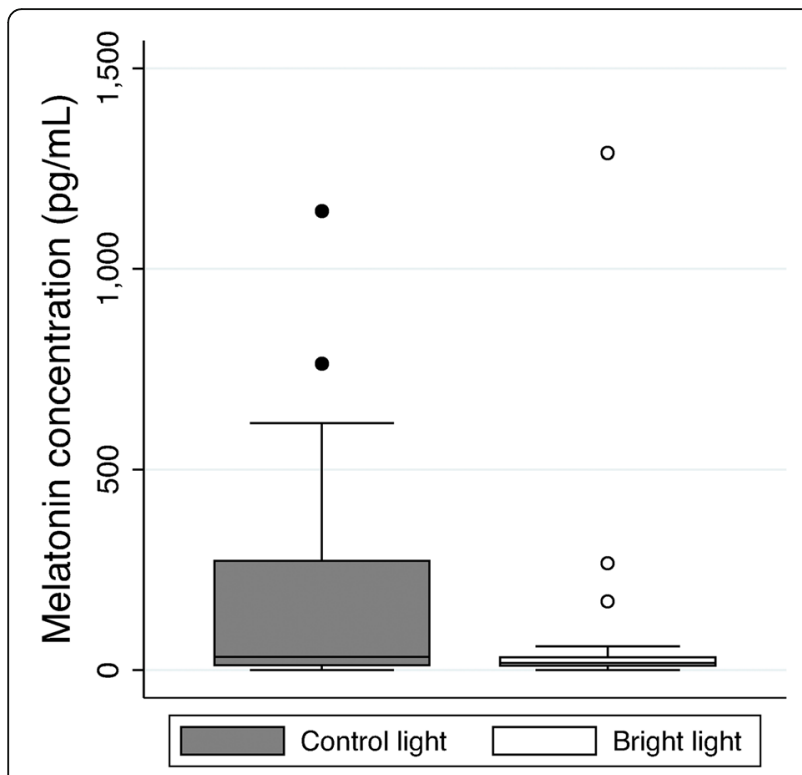

Fig. 4 Salivary melatonin concentrations

for us to assess PVT and SSS parameters at $0500 \mathrm{~h}$. Several interventions have been studied as measures to counter the degradation causing fatigue, though light, the predominant cue entraining circadian biology and sleep/wake cycles, has been the focus of particularly intense investigation [11, 12]. Exposing human subjects during the early biological night to either 106 or $9100 \mathrm{~lx}$, relative to $3 \mathrm{~lx}$, has been shown to acutely suppress plasma melatonin, advance the time of the circadian pacemaker, and increase alertness, as assessed by the Karolinskia Sleepiness Scale (KSS) and Karolinska Drowsiness Test (KDT) [28]. Additional studies have had similar results, with reduced sleepiness and fatigue independent of whether the exposure to high (i.e., $5000 \mathrm{~lx}$ ) illuminance occurred during the day or night $[29,30]$. These data support that varying brightness even within the typical range of ambient lighting can significantly improve subject alertness. However, the control conditions utilized by these studies approximated complete darkness and are distinct from the lighting typical of an ICU (i.e., 100 and $300 \mathrm{~lx}$ ). Thus, heightening alertness and performance in this latter hospital environment may prove more challenging.

In this vein, contemporary studies have shown that hospital night shift workers exposed to either short photoperiods of high intensity light or dynamic lighting that replicated daylight variations felt more alert and well-rested after sleep [5, 16]. In a study of 113 ICU nurses, subjects exposed to dynamic lighting that replicated natural daylight variations experienced more effective sleep; however, this study did not assess parameters of alertness or vigilance during the actual night shift [5]. In a simulated shift work protocol, exposure to modestly bright (> $2000 \mathrm{~lx}$ ) white light at night improved alertness and attention, preserved sleep duration following the night shift, reduced response times and lapses on the PVT, and advanced circadian timing relative to the control group exposed to ambient (100 lx) lighting [31]. These later results are compelling, though the simulated laboratory conditions render them difficult to generalize to the actual workplace. In a more "real world" assessment of the ramifications of altering light within a hospital setting, a 10-min exposure to bright $(5000 \mathrm{~lx}$ at $40 \mathrm{~cm}$ ) light prior to the day shift (0800-1700 h) reduced sleepiness and reduced mean response time on the PVT at $1000 \mathrm{~h}$, though no significant difference was observed in any parameter later in the day [32]. A more recent study of ICU nurses reported that cognitive performance, self-reported depressive signs and symptoms, and fatigue did not differ significantly between exposure to $1700 \mathrm{~lx}$ during the day time versus $300 \mathrm{~lx}$ in control settings [19]. These data suggest that a higher illuminance environment may prove beneficial to both the day and night shift worker, but that there is likely a lower threshold of light illuminance and of exposure duration.

Our trial was one of effectiveness and evaluated the effects of bright white light on ICU nurse vigilance during a working night shift. Though sleepiness towards the conclusion of the shift was reduced, high illuminance failed to beneficially effect several parameters of the PVT, such as mean response times and lapses. Notably, and certainly relevant to the delivery of healthcare, there was an increase in errors after prolonged exposure to bright white light. Other investigators have similarly reported that altering the night lighting environment may yield counter-intuitive cognitive or behavioral results. In a study of simulated driving at early night, blue-enriched white light enhanced physiological arousal but did not correlate with improved cognition; indeed, blue light produced larger driving errors than amber light [33]. The authors concluded that excessive arousal might deteriorate accuracy in complex tasks requiring precision, in this case driving [33]. We similarly consider this mechanism as a plausible underlying cause of our paradoxical results.

Emerging data suggest that a shorter spectrum, such as blue light, may have a greater impact on modulating circadian rhythms and heightening alertness [15]. Melanopsin, the circadian photopigment of the eye has a peak absorption of $467 \mathrm{~nm}$, and thus, it is light of the lower wavelength, visible blue spectrum that maximally entrains circadian biological processes [34-36]. Several studies have evaluated whether blue light more effectively enhances alertness and performance [37]. In a before-after intervention study of 30 night-shift workers, blue-enriched white light improved alertness and decreased omission errors and reaction times, markers of 
cognitive performance [38]. Low illuminance white light rich in the blue spectrum improved subjective sleepiness in night shift workers when it was applied at night between 2300 and 0700 h) [39]. However, the effects of blue-enriched light may be context dependent; in particular, dependent upon the complexity of task performance [33].

One suggested mechanism by which light enhances alertness is through suppression of nocturnal melatonin, the biological mediator of sleep [13]. Several studies have evaluated the suppression of melatonin by phototherapy [39-41], and tested correlation between the physiologic effects of light, including reduced sleepiness and task performance improvement, and reduced melatonin concentration [42]. We too observed reduced melatonin with our intervention of high illuminance, though this was not statistically significant. Unfortunately, salivary samples were not collected from every nurse, which likely limited our power. Alternatively, our study used a much longer photoperiod of high illuminance light, and the mechanism of melatonin suppression could have been exhausted towards the end of shift. Nonetheless, caution must be exercised, as long-term shift work causing reduced melatonin levels has been linked to an elevated risk of a variety of diseases, including cancer [43].

Night shifts force individuals to work at a time when the circadian drive to sleep is high and then to sleep when wakefulness is high. This misalignment induces poor daytime sleep and impaired nighttime alertness [7]. Thus, the ideal intervention will not only improve nocturnal alertness and performance during the shift, but also encourage a rapid onset of sleep, post-shift. In the context of altering the environment, this optimal intervention has yet to be identified. However, the evidence suggests that the period of transition to the day (i.e., the morning) is equally important, insofar as achieving the objective of improved daytime sleep. In a study of bright light exposure at night, a second cohort underwent bright light exposure followed by light attenuation in the morning with the simple intervention of sunglasses. Both groups exhibited improved nocturnal alertness, but only the bright light/sunglasses group experienced improved post-shift daytime sleep. These data suggest that nocturnal alertness and daytime sleep in night shift workers is improved with bright light exposure in their work place, but maximized by attenuating light the following morning prior to daytime sleep [44]. Others have reported similar observations $[45,46]$. Even more recent data suggest that a "one size fits all" approach is insufficient, and that a personalized approach accounting for the individual's baseline circadian phase is needed [47]. Additional studies propose a biological rationale for an effect on sleep of a differential response to light [48].

\section{Conclusion}

In conclusion, we observed that altering the lighting environment of ICU nurses working the night shift to bright light reduced their sleepiness but led to an increased number of errors. As the need for healthcare is independent of the time on the clock, so too the demand for night shift workers is likely to expand. Further studies are required to identify the optimal illuminance, photoperiod and wavelength of light that will best foster circadian realignment, and thereby enhance nighttime vigilance and performance, improve daytime sleep efficiency, and ultimately improve the wellbeing of our night shift nurses and their delivery of care.

\section{Abbreviations \\ ICU: Intensive care unit; IRB: Institutional Review Board; Ix: Lux; PVT: Psychomotor vigilance task; SSS: Stanford sleepiness scale; SWSD: Shift work sleep disorder \\ Acknowledgements \\ Not applicable. \\ Funding \\ This work supported by National Institutes of Health grant R01 GM082852 (MRR) and R01 GM116929. (MRR).}

\section{Availability of data and materials \\ All data generated or analyzed during this study are available from the corresponding author on request.}

\section{Authors' contributions}

JEG was involved in the conception and design of the study, the collection and interpretation of data, manuscript preparation, and final revision and approval of the manuscript. HEL was involved in the collection and interpretation of data and final revision and approval of the manuscript. SRG was involved in the design of the study and final revision and approval of the manuscript. MRR was involved in the conception and design of the study, the collection and interpretation of data, manuscript preparation, and final revision and approval of the manuscript.

\section{Ethics approval and consent to participate}

This study was approved by the IRB at the University of Pittsburgh (PRO\#17010109). Subjects were enrolled after written informed consent was obtained.

\section{Consent for publication \\ Not applicable.}

\section{Competing interests}

The authors declare that they have no competing interests.

\section{Publisher's Note}

Springer Nature remains neutral with regard to jurisdictional claims in published maps and institutional affiliations.

Received: 27 June 2018 Accepted: 15 October 2018

Published online: 13 November 2018

\section{References}

1. Richter K, Acker J, Adam S, Niklewski G. Prevention of fatigue and insomnia in shift workers-a review of non-pharmacological measures. EPMA J. 2016; 7(1). https://doi.org/10.1186/s13167-016-0064-4.

2. Ahasan R, Lewko J, Campbell D, Salmoni A. Adaptation to night shifts and synchronisation processes of night workers. J Physiol Anthropol Appl Human Sci. 2001;20(4):215-26 Available from: http://www.ncbi.nlm.nih.gov/ pubmed/11575184. 
3. American Sleep Disorders. In: American Academy of Sleep Medicine, editor. The international classification of sleep disorders: diagnostic and coding manual. 2nd ed. Westchester: American Sleep Disorders; 1997.

4. Fritschi L, Glass DC, Heyworth JS, Aronson K, Girschik J, Boyle T, et al. Hypotheses for mechanisms linking shiftwork and cancer. Med Hypotheses. 2011;77(3):430-6 Available from: http://dx.doi.org/10.1016/j.mehy.2011.06.002

5. Jensen HI, Markvart J, Holst R, Thomsen TD, Larsen JW, Eg DM, et al. Shift work and quality of sleep: effect of working in designed dynamic light. Int Arch Occup Environ Health. 2016;89(1):49-61 Available from: http://dx.doi. org/10.1007/s00420-015-1051-0.

6. Khamisa N, Peltzer K, Oldenburg B. Burnout in relation to specific contributing factors and health outcomes among nurses: a systematic review. Int J Environ Res Public Health. 2013;10(6):2214-40.

7. Chapdelaine S, Paquet J, Dumont M. Effects of partial circadian adjustments on sleep and vigilance quality during simulated night work. J Sleep Res. 2012;4:380-9 Available from: http://www.ncbi.nlm.nih.gov/pubmed/ 22329989.

8. Lauber JK, Kayten PJ. Sleepiness, circadian dysrhythmia, and fatigue in transportation system accidents. Sleep. 1988;11(6):503-12 Available from: http://www.ncbi.nlm.nih.gov/pubmed/3238253.

9. Smith AP, Kendrick AM, Maben AL. Effects of breakfast and caffeine on performance and mood in the late morning and after lunch. Neuropsychobiology. 1992;26(4):198-204 Available from: http://www.ncbi. nlm.nih.gov/pubmed/1299795.

10. Horne JA, Reyner LA. Sleep related vehicle accidents. BMJ. 1995;310(6979): 565-7 Available from: http://www.ncbi.n/m.nih.gov/pubmed/7888930.

11. Cajochen C. Alerting effects of light. Sleep Med Rev. 2007;11(6):453-64 Available from: http://www.ncbi.nlm.nih.gov/pubmed/17936041.

12. Chellappa SL, Gordijn MCM, Cajochen C. Can light make us bright? Effects of light on cognition and sleep. Prog Brain Res. 2011;190:119-33 Available from: http://www.ncbi.n/m.nih.gov/pubmed/21531248.

13. Kayumov L, Casper RF, Hawa RJ, Perelman B, Chung SA, Sokalsky S, et al. Blocking low-wavelength light prevents nocturnal melatonin suppression with no adverse effect on performance during simulated shift work. J Clin Endocrinol Metab. 2005;90(5):2755-61.

14. Berson DM, Dunn FA, Takao M. Phototransduction by retinal ganglion cells that set the circadian clock. Science. 2002;295(5557):1070-3 Available from: \%5C\%5CRoot\%5Cgroups\%5CElectronic Library\%5C300040.

15. Sasseville A, Martin JS, Houle J, Hébert M. Investigating the contribution of short wavelengths in the alerting effect of bright light. Physiol Behav. 2015; 151:81-7 Available from: http://dx.doi.org/10.1016/j.physbeh.2015.06.028.

16. Iwata N, Ichii S, Egashira K. Effects of bright artificial light on subjective mood of shift work nurses. Ind Health. 1997;35(1):41-7 Available from: http://joi.jlc.jst.go.jp/JST.Journalarchive/indhealth1963/35.41?from=CrossRef

17. Huang LB, Tsai MC, Chen CY, Hsu SC. The effectiveness of light/dark exposure to treat insomnia in female nurses undertaking shift work during the evening/night shift. J Clin Sleep Med. 2013;9(7):641-6.

18. van Bommel WJM. Non-visual biological effect of lighting and the practical meaning for lighting for work. Appl Ergon. 2006;37(4 SPEC. ISS):461-6.

19. Simons KS, Boeijen ERK, Mertens MC, Rood P, de Jager CPC, van den Boogaard M. Effect of dynamic light application on cognitive performance and well-being of intensive care nurses. Am J Crit Care. 2018;27(3):245-8 Available from: http://www.ncbi.nlm.nih.gov/pubmed/29716912.

20. Basner M, Mollicone D, Dinges DF. Validity and sensitivity of a brief psychomotor vigilance test (PVT-B) to total and partial sleep deprivation. Acta Astronaut. 2011;69(11-12):949-59 Available from: http://www.ncbi.nlm. nih.gov/pubmed/22025811.

21. Thomann J, Baumann CR, Landolt HP, Werth E. Psychomotor Vigilance Task demonstrates impaired vigilance in disorders with excessive daytime sleepiness. J Clin Sleep Med. 2014;10(9):1019-24.

22. Lim J, Dinges DF. Sleep deprivation and vigilant attention. Ann N Y Acad Sci. 2008;1129:305-22

23. Kozaki T, Lee S, Nishimura T, Katsuura T, Yasukouchi A. Effects of saliva collection using cotton swabs on melatonin enzyme immunoassay. J Circadian Rhythms. 2011;9(1):1.

24. Hoddes E, Zarcone V, Smythe H, Phillips R, Dement WC. Quantification of sleepiness: a new approach. Psychophysiology. 1973;10(4):431-6 Available from: http://www.ncbi.nlm.nih.gov/pubmed/4719486.

25. Parshuram CS, Amaral ACKB, Ferguson ND, Baker GR, Etchells EE, Flintoft V, et al. Patient safety, resident well-being and continuity of care with different resident duty schedules in the intensive care unit: a randomized trial. CMAJ.
2015;187(5):321-9 Available from: http://www.ncbi.nlm.nih.gov/pubmed/ 25667258.

26. Slanger TE, Gross JV, Pinger A, Morfeld P, Bellinger M, Duhme A-L, et al. Person-directed, non-pharmacological interventions for sleepiness at work and sleep disturbances caused by shift work. Cochrane database Syst Rev. 2016;23(8):CD010641 Available from: http://www.ncbi.nlm.nih.gov/pubmed/ 27549931.

27. Eastman Cl, Boulos Z, Terman M, Campbell SS, Dijk DJ, Lewy AJ. Light treatment for sleep disorders: consensus report. VI. Shift work. J Biol Rhythms. 1995;10(2):157-64 Available from: http://journals.sagepub.com/ doi/10.1177/074873049501000208.

28. Cajochen C, Zeitzer JM, Czeisler CA, Dijk DJ. Dose-response relationship for light intensity and ocular and electroencephalographic correlates of human alertness. Behav Brain Res. 2000;115(1):75-83 Available from: http://www. ncbi.nlm.nih.gov/pubmed/10996410.

29. Rüger M, Gordijn MCM, Beersma DGM, de Vries B, Daan S. Time-of-daydependent effects of bright light exposure on human psychophysiology: comparison of daytime and nighttime exposure. Am J Physiol Regul Integr Comp Physiol. 2006;290(5):R1413-20 Available from: http://www.ncbi.nlm. nih.gov/pubmed/16373441.

30. Phipps-Nelson J, Redman JR, Dijk D-J, SMW R. Daytime exposure to bright light, as compared to dim light, decreases sleepiness and improves psychomotor vigilance performance. Sleep. 2003;26(6):695-700 Available from: http://www.ncbi.nlm.nih.gov/pubmed/14572122.

31. Chinoy ED, Harris MP, Kim MJ, Wang W, Duffy JF. Scheduled evening sleep and enhanced lighting improve adaptation to night shift work in older adults. Occup Environ Med. 2016;73(12):869-76 Available from: http://www. ncbi.nlm.nih.gov/pubmed/27566781.

32. Tanaka K, Takahashi M, Tanaka M, Takanao T, Nishinoue N, Kaku A, et al. Brief morning exposure to bright light improves subjective symptoms and performance in nurses with rapidly rotating shifts. J Occup Health. 2011; 53(4):258-66 Available from: http://www.ncbi.nlm.nih.gov/pubmed/ 21597232.

33. Rodríguez-Morilla B, Madrid JA, Molina E, Correa A. Blue-enriched white light enhances physiological arousal but not behavioral performance during simulated driving at early night. Front Psychol. 2017;8:997 Available from: http://www.ncbi.nlm.nih.gov/pubmed/28690558.

34. Matsuyama T, Yamashita T, Imamoto Y, Shichida Y. Photochemical properties of mammalian melanopsin. Biochemistry. 2012;51(27):5454-62 Available from: http://www.ncbi.nlm.nih.gov/pubmed/22670683.

35. Narasimamurthy R, Hatori M, Nayak SK, Liu F, Panda S, Verma IM. Circadian clock protein cryptochrome regulates the expression of proinflammatory cytokines. Proc Natl Acad Sci U S A. 2012;109(31):12662-7 Available from: http://www.ncbi.nlm.nih.gov/pubmed/22778400

36. Sancar A. Regulation of the mammalian circadian clock by cryptochrome. J Biol Chem. 2004;279(33):34079-82 Available from: http://www.ncbi.nlm.nih. gov/pubmed/15123698.

37. Rüger M, St Hilaire MA, Brainard GC, Khalsa S-BS, Kronauer RE, Czeisler CA, et al. Human phase response curve to a single $6.5 \mathrm{~h}$ pulse of short-wavelength light. J Physiol. 2013;591(1):353-63 Available from: http://www.ncbi.nlm.nih. gov/pubmed/23090946.

38. Motamedzadeh M, Golmohammadi R, Kazemi R, Heidarimoghadam R. The effect of blue-enriched white light on cognitive performances and sleepiness of night-shift workers: a field study. Physiol Behav. 2017;177:20814 Available from: http://www.ncbi.nlm.nih.gov/pubmed/28495465.

39. Sletten TL, Ftouni S, Nicholas CL, Magee M, Grunstein RR, Ferguson S, et al. Randomised controlled trial of the efficacy of a blue-enriched light intervention to improve alertness and performance in night shift workers. Occup Environ Med. 2017;74(11):792-801 Available from: http://www.ncbi. nlm.nih.gov/pubmed/28630378.

40. Visser EK, Beersma DG, Daan S. Melatonin suppression by light in humans is maximal when the nasal part of the retina is illuminated. J Biol Rhythms. 1999;14(2):116-21 Available from: http://www.ncbi.nlm.nih.gov/pubmed/ 10194647.

41. Horowitz TS, Cade BE, Wolfe JM, Czeisler CA. Efficacy of bright light and sleep/darkness scheduling in alleviating circadian maladaptation to night work. Am J Physiol Endocrinol Metab. 2001;281(2):E384-91 Available from: http://www.ncbi.nlm.nih.gov/pubmed/11440916.

42. Paul MA, Miller JC, Gray G, Buick F, Blazeski S, Arendt J. Circadian phase delay induced by phototherapeutic devices. Aviat Space Environ Med. 2007;78(7): 645-52 Available from: http://www.ncbi.nlm.nih.gov/pubmed/17679560. 
43. Leung M, Tranmer J, Hung E, Korsiak J, Day AG, Aronson KJ. Shift work, chronotype, and melatonin patterns among female hospital employees on day and night shifts. Cancer Epidemiol Biomark Prev. 2016;25(5):830-8.

44. Yoon I-Y, Jeong D-U, Kwon K-B, Kang S-B, Song B-G. Bright light exposure at night and light attenuation in the morning improve adaptation of night shift workers. Sleep. 2002;25(3):351-6 Available from: http://www.ncbi.nlm. nih.gov/pubmed/12003167.

45. Boivin DB, Boudreau P, James FO, Kin NM. Photic resetting in night-shift work: impact on nurses' sleep. Chronobiol Int. 2012;29(5):619-28 Available from: http://www.ncbi.nlm.nih.gov/pubmed/22621359.

46. Crowley SJ, Lee C, Tseng CY, Fogg LF, Eastman Cl. Combinations of bright light, scheduled dark, sunglasses, and melatonin to facilitate circadian entrainment to night shift work. J Biol Rhythms. 2003;18(6):513-23 Available from: http://www.ncbi.nlm.nih.gov/pubmed/14667152.

47. Stone JE, Sletten TL, Magee M, Ganesan S, Mulhall MD, Collins A, et al. Temporal dynamics of circadian phase shifting response to consecutive night shifts in healthcare workers: role of light-dark exposure. J Physiol. 2018;596(12):2381-95 Available from: http://www.ncbi.nlm.nih.gov/pubmed/ 29589871.

48. Chellappa SL, Viola AU, Schmidt C, Bachmann V, Gabel V, Maire M, et al. Light modulation of human sleep depends on a polymorphism in the clock gene Period3. Behav Brain Res. 2014;271:23-9 Available from: http://www. ncbi.nlm.nih.gov/pubmed/24893318.

Ready to submit your research? Choose BMC and benefit from:

- fast, convenient online submission

- thorough peer review by experienced researchers in your field

- rapid publication on acceptance

- support for research data, including large and complex data types

- gold Open Access which fosters wider collaboration and increased citations

- maximum visibility for your research: over $100 \mathrm{M}$ website views per year

At $\mathrm{BMC}$, research is always in progress.

Learn more biomedcentral.com/submissions 